\title{
AUGMENTED REALITY PADA METAMORFOSIS LEBAH (APIS SP.) SEBAGAI MEDIA PEMBELAJARAN
}

\author{
Ospa Pea Yuanita Meishanti*, Zaidatur Roziqo** \\ * Departement of Biology Education,KH. A. Wahab Hasbullah University \\ ** Departement of Biology Education, KH. A. Wahab Hasbullah University \\ Correspondence Author: ospapea@unwaha.ac.id
}

\begin{tabular}{|c|c|}
\hline Info Artikel : & ABSTRACT \\
\hline $\begin{array}{l}\text { Sejarah Artikel : } \\
\text { Menerima : } \\
\text { 12 Des 2020 } \\
\text { Revisi : } \\
\text { 03 Jan 2021 } \\
\text { Diterima : } \\
\text { 16 Jan 2021 } \\
\text { Online : } \\
\text { 26 Jan 2021 }\end{array}$ & $\begin{array}{l}\text { Augmented Reality is actually not something foreign to the general public, it's } \\
\text { just that they don't know what Augmented Reality itself means, Augmented } \\
\text { Reality cards can generally be found in some snacks, which the cards can be } \\
\text { scanned through a special application available on the Playstore. However, } \\
\text { currently researchers are making Augmented Reality for learning, in this case } \\
\text { researchers are using bee metamorphosis, so learning becomes more } \\
\text { interesting. This study aims to describe the feasibility of Augmented Reality } \\
\text { media for bee metamorphosis and to determine student responses to the } \\
\text { attractiveness of Augmented Reality media for bee metamorphosis. The } \\
\text { development model used is the ADDIE model which includes: Analysis, } \\
\text { Design, Development, Implementation and Evaluation. Products are validated } \\
\text { by one media expert and one material expert. The attractiveness test was } \\
\text { carried out on } 5 \text { students of MTs Al-Ihsan Kalijaring Jombang. Data obtained } \\
\text { from media experts, namely } 80 \% \text { with proper qualifications, criteria from } \\
\text { material experts, namely } 88 \% \text { with very decent qualifications, while from the } \\
\text { data students get a score of } 88.75 \% \text { with qualifications strongly attractiveness. } \\
\text { The results of the assessment of media experts, material experts and student } \\
\text { responses show that the bee metamorphosis Augmented Reality proper } \\
\text { qualifications can be used as a learning media. }\end{array}$ \\
\hline & INTISARI \\
\hline $\begin{array}{l}\text { Kata Kunci : } \\
\text { Augmented } \\
\text { Reality, } \\
\text { Pengembangan, } \\
\text { Media } \\
\text { Pembelajaran, }\end{array}$ & $\begin{array}{l}\text { Augmented Reality sebenarnya bukan sesuatu yang asing dalam masyarakat } \\
\text { umumnya dalam bentuk kartu yang dapat ditemukan pada beberapa snack } \\
\text { kemasan yang mana kartu tersebut dapat di-scan melalui aplikasi khusus yang } \\
\text { tersedia dalam Playstore. Namun sekarang peneliti membuat Augmented } \\
\text { Reality untuk pembelajaran, dalam hal ini peneliti menggunakan bahasan } \\
\text { metamorfosis lebah, agar pembelajaran lebih menarik. Penelitian ini } \\
\text { bertujuan untuk mendeskripsikan kelayakan media Augmented Reality pada } \\
\text { metamorfosis lebah dan mengetahui respon siswa terhadap kemenarikan } \\
\text { media Augmented Reality metamorfosis lebah. Model pengembangan yang } \\
\text { digunakan adalah model ADDIE yang meliputi: Analysis, Design, } \\
\text { Development, Implementation dan Evaluation. Produk divalidasi oleh satu } \\
\text { ahli media dan satu ahli materi. Uji kemenarikan dilakukan pada } 5 \text { orang } \\
\text { siswa MTs Al-Ihsan Kalijaring Jombang. Data penilaian yang diperoleh dari } \\
\text { ahli media yaitu sebesar } 80 \% \text { dengan kualifikasi layak, penilaian dari ahli } \\
\text { materi yaitu sebesar } 88 \% \text { dengan kualifikasi sangat layak, sedangkan dari } \\
\text { data respon siswa mendapatkan skor sebesar 88,75\% dengan kualifikasi }\end{array}$ \\
\hline
\end{tabular}

ISSN Print $\quad: 1979-7141$

ISSN Online : 2541-1942 


\begin{tabular}{|l|l|}
\hline & $\begin{array}{l}\text { sangat setuju. Hasil penilaian dari ahli media, ahli materi dan respon siswa } \\
\text { menunjukkan Augmented Reality metamorfosis lebah layak dapat digunakan } \\
\text { sebagai media pembelajaran. }\end{array}$ \\
\hline
\end{tabular}

\section{PENDAHULUAN}

Ki Hajar Dewantara mengemukakan bahwa pendidikan merupakan tuntutan di dalam tumbuhnya anak-anak, dalam arti pendidikan menuntun segala kekuatan kodrat yang ada pada anak-anak itu, agar mereka sebagai manusia dan sebagai anggota masyarakat dapat mencapai keselamatan dan kebahagian setinggi-tingginya. Pendidikan adalah kegiatan menerima dan memberikan pengetahuan sehingga kebudayaan dapat diteruskan dari generasi ke generasi berikutnya, pendidikan juga merupakan suatu proses individu untuk mengembangkan bakat, kekuatan, kesanggupan dan minatnya (Tim Dosen Jurusan Administrasi Pendidikan, 2008). Pendidikan merupakan salah satu bentuk perwujudan budaya manusia yang dinamis dan kebutuhan pembangunan (Meishanti 2020). Dalam keseluruhan proses pendidikan di sekolah sebagian besar kegiatan belajar mengajar berhasil atau tidak, prestasi belajar siswa sangat bergantung pada bagaimana proses pembelajaran tersebut (Meishanti 2018). Keberhasilan suatu proses belajar mengajar di kelas tergantung pada komponennya, antara lain siswa, kurikulum, guru, metode, sarana prasarana, media, dan lingkungan (Meishanti 2019). Pendidik sebagai pelaksana pendidikan tidak hanya dituntut untuk mampu menguasai materi yang diajarkan. Pendidik juga harus mampu berkreasi mengembangkan media pembelajaran yang inovatif, variatif, menarik, kontekstual, dan sesuai dengan tingkat kebutuhan peserta didik. Hal-hal tersebut akan menjadi penentu kompetensi yang akan dicapai dan dimiliki peserta didik setelah berlangsungnya proses kegiatan belajar mengajar. Media pembelajaran merupakan suatu alat perantara antara pendidik dengan peserta didik dalam pembelajaran yang mampu menghubungkan, memberi informasi dan menyalurkan pesan sehingga tercipta proses pembelajaran yang efektif dan efisien. Apabila dalam proses pembelajaran tidak menggunakan media maka tidak akan terjadi proses pembelajaran (Mustaqim, 2016). Salah satu bentuk media pembelajaran adalah media pembelajaran berbasis teknologi komputer, misalnya Augmented Reality (AR).Augmented Reality (AR) merupakan suatu konsep perpaduan antara virtual reality dengan world reality, sehingga objek-objek virtual 2 Dimensi (2D) atau 3 Dimensi (3D) seolah-olah terlihat nyata dan menyatu dengan dunia nyata. Pada teknologi $\mathrm{AR}$, pengguna dapat melihat dunia nyata yang ada di sekelilingnya dengan penambahan obyek virtual yang dihasilkan oleh komputer (Mustika, 2015).

Augmented Reality $(A R)$ merupakan suatu konsep perpaduan antara virtual reality dengan world reality, sehingga objek-objek virtual 2 Dimensi (2D) atau 3 Dimensi (3D) seolah-olah terlihat nyata dan menyatu dengan dunia nyata. Pada teknologi AR, pengguna dapat melihat dunia nyata yang ada di sekelilingnya dengan penambahan obyek virtual yang dihasilkan oleh komputer (Mustika, 2015). Augmented Reality (AR) pertama kali diimplementasikan oleh Ivan Sutherland pada tahun 1962. Augmented Reality sebagai sebuah metodologi pun telah banyak dikembangkan oleh berbagai pihak sehingga dapat diimplementasikan ke berbagai perangkat. Penerapan Augmented Reality juga tidak membutuhkan perangkat tambahan khusus yang pada umumnya memakan banyak dana dan waktu untuk pembelian serta proses instalasi (Young, 2015). Penulis ingin memanfaatkan keunggulan AR untuk membantu memvisualisasikan konsep biologi yang bersifat abstrak menjadi lebih intuitif untuk meningkatkan pemahaman peserta didik dalam menggambarkan suatu objek. Keunggulan Augmented Reality dibandingkan sistem yang menggunakan metode Virtual Reality, diantaranya:interaksi terasa begitu nyata, implementasi lebih murah, kemungkinan tersendatnya sistem yang ditampilkan lebih sedikit (Young, 20

ISSN Print : : 1979-7141

ISSN Online : 2541-1942 
2015).Pengembangan media Augmented Reality ini diharapkan mampu meningkatkan minat belajar peserta didik pada materi metamorfosis lebah.

Media pembelajaran Augmented Reality pada metamorfosis lebah ini belum pernah dikembangkan sebelumnya. Adapun Augmented Reality metamorfosis yang sudah dikembangkan yaitu pada metamorfosis kupu-kupu, metamorfosis belalang dan metamorfosis katak, sehingga perlu dibuat media Augmented Reality (AR) pada metamorfosis lebah madu (Apis sp.).

Adapun tujuan penelitian pengembangan ini yaitu untuk mendeskripsikan kelayakan media pembelajaran Augmented Reality (AR) pada metamorfosis lebah yang akan dikembangkan dalam penelitian ini dan untuk mengetahui respon siswa terhadap kemenarikan media Augmented Reality $(A R)$ materi metamorfosis lebah.

\section{METODE PENELITIAN}

Metode penelitian ini menggunakan model pengembangan ADDIE dengan 5 tahapan yaitu Analysis (analisis), Design (desain), Development (pengembangan), Implementation (implementasi) dan Evaluation (evaluasi). Pada tahap analisis, kegiatan utama adalah menganalisis perlunya pengembangan media Augmented Reality (AR) dalam proses pembelajaran.

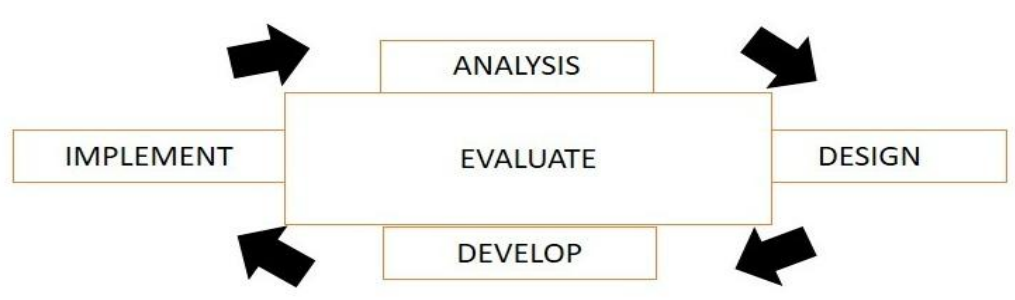

Gambar 2.1 Tahapan Model Pengembangan ADDIE

Tahap desain adalah mendesain media pembelajaran setelah dilakukan analisis kebutuhan dengan merancang storyboard. Tahap selanjutnya pengembangan yaitu mengembangkan media pembelajaran dari storyboard yang telah dibuat. Tahap implementasi yaitu melakukan uji coba kepada siswa. Dan terakhir yaitu evaluasi yang dilakukan apabila produk belum dikatakan valid.

Media pembelajaran Augmented Reality metamorfosis lebah divalidasi oleh ahli media dari Universitas KH. A. Wahab Hasbullah dan ahli materi dari guru mata pelajaran IPA MTs AlIhsan Kalijaring Jombang. Uji coba produk dilakukan oleh siswa MTs Al-Ihsan Kalijaring Jombang. Dalam instrumen pengumpulan data peneliti menggunakan angket. Hasil yang diperoleh dari analisis data digunakan sebagai acuan untuk merevisi aplikasi media pembelajaran yang dikembangkan. Data yang diperoleh dari validasi ahli dan respon siswa dianalisis dengan menggunakan rumus berikut:

$$
P=\frac{\sum x}{\sum x_{i}} x 100 \%
$$

ISSN Print $\quad: 1979-7141$

ISSN Online : 2541-1942 
Keterangan:

$\mathrm{P} \quad=$ Besar presentase

$\sum x \quad=$ Jumlah total skor yang diperoleh dari validator atau responden (siswa)

$\sum x_{i} \quad=$ Jumlah skor maksimal yang diharapkan

Hasil persentase angket dianalisis menggunakan kualifikasi penilaian hasil validasi dan respon siswa yang ditunjukkan pada Tabel 3.1.

Tabel 2.1 Kualifikasi Penilaian Hasil Validasi dan Respon Siswa

\begin{tabular}{ccc}
\hline Skor & Ahli & Respon Siswa \\
\hline $81-100$ & Sangat Layak & Sangat Setuju \\
\hline $61-80$ & Layak & Setuju \\
\hline $41-60$ & Cukup Layak & Kurang Setuju \\
\hline $21-40$ & Kurang Layak & Tidak Setuju \\
\hline $0-20$ & Tidak Layak & Sangat Tidak Setuju \\
\hline
\end{tabular}

(Sumber: Modifikasi dari Riduwan, 2012)

\section{HASIL DAN ANALISA}

Berdasarkan model pengembangan ADDIE, berikut adalah hasil dan pembahasan media Augmented Reality pada metamorfosis lebah.

1. Analysis (analisis)

Pada tahap ini, kegiatan utama adalah menganalisis perlunya pengembangan media Augmented Reality (AR) dalam proses pembelajaran. Pengembangan media Augmented Reality $(A R)$ diawali oleh adanya masalah dalam pembelajaran yang sudah diterapkan dan media yang digunakan kurang menarik, setelah melakukan analisis masalah tersebut perlunya pengembangan media yang menarik, sehingga peneliti membuat suatu media berupa pengembangan media Augmented Reality (AR).

2. Design (desain)

Mendesain media pembelajaran adalah langkah yang akan dilakukan setelah melakukan analisis kebutuhan. Kegiatan perencanaan awal yang dilakukan peneliti adalah merancang kerangka konseptual Augmented Reality (AR), dan merancang storyboard tampilan Augmented Reality.

3. Development (pengembangan)

Development dalam model ADDIE berisi kegiatan realisasi rancangan produk. Dalam tahap desain, telah disusun kerangka konseptual penerapan media Augmented Reality (AR).

Dalam tahap pengembangan, kerangka yang masih konseptual tersebut direalisasikan menjadi produk yang siap diimplementasikan.

Media pembelajaran Augmented Reality (AR) pada metamorfosis lebah di validasi oleh 2 validator yaitu Ino Angga Putra, M.Pd. sebagai ahli media, Eny Widiastutik, S.Pd. sebagai ahli materi, dan 5 responden dari MTs Al- Ihsan Kalijaring Jombang. Penyajian data penelitian dari validator ahli media dapat dilihat pada tabel 3.1 dan validator ahli media pada tabel 3.2 
Tabel 3.1 Data Hasil Tabel Oleh Ahli Media

\begin{tabular}{|c|c|c|c|c|c|}
\hline \multirow{2}{*}{ No } & \multirow{2}{*}{ Kriteria } & \multicolumn{3}{|c|}{ Skor } & \multirow{2}{*}{ Keterangan } \\
\hline & & $\mathbf{X}$ & $\mathbf{X i}$ & $\%$ & \\
\hline 1. & $\begin{array}{l}\text { Efektif dan efisien dalam pengembangan } \\
\text { dan penggunaan media pembelajaran }\end{array}$ & 3 & 5 & 60 & Cukup Layak \\
\hline 2. & $\begin{array}{l}\text { Media Augmented Reality (AR) layak } \\
\text { digunakan }\end{array}$ & 4 & 5 & 80 & Layak \\
\hline 3. & $\begin{array}{l}\text { Media Augmented Reality (AR) mudah } \\
\text { dioperasikan }\end{array}$ & 5 & 5 & 100 & Sangat Layak \\
\hline 4. & $\begin{array}{l}\text { Media Augmented Reality }(A R) \text { mudah } \\
\text { dipahami }\end{array}$ & 5 & 5 & 100 & Sangat Layak \\
\hline 5. & Gambar atau video menarik & 4 & 5 & 80 & Layak \\
\hline 6. & Audio jelas & 4 & 5 & 80 & Layak \\
\hline 7. & $\begin{array}{l}\text { Visual menarik (meliputi: tampilan, warna } \\
\text { dan huruf) }\end{array}$ & 4 & 5 & 80 & Layak \\
\hline 8. & Kreatif dalam ide dan penuangan gagasan & 3 & 5 & 60 & Cukup Layak \\
\hline & JUMLAH & 32 & 40 & 80 & Layak \\
\hline
\end{tabular}

Keterangan:

$\mathrm{X}=$ Skor dari Ahli Media

$\mathrm{Xi}=$ Skor Maksimal

Total jawaban yang diperoleh dari ahli media adalah 32 dan skor maksimal dari jawaban secara keseluruhan adalah 40 maka dari perolehan skor keseluruhan dari ahli media diatas diperoleh nilai rata-rata $80 \%$ dengan kriteria layak. Aspek efektif dan efisien dalam pengembangan dan penggunaan belajar dan aspek kreatif dalam ide dan penuangan gagasan mendapat nilai rata-rata 60\% dengan kriteria 'cukup layak'. Aspek media Augmented Reality (AR) layak digunakan, aspek gambar atau video menarik, aspek audio jelas, dan aspek visual menarik ( meliputi: tampilan, warna, dan huruf) mendapatkan nilai rata-rata $80 \%$. Dari penilain tersebut dapat disimpulkan bahwa perlu adanya perbaikan lebih lanjut dari segi media agar media lebih layak diterapkan dalam proses pembelajaran. Kritik dan saran dari ahli media yaitu kartu Augmented Reality (AR) di desain seperti kartu remi dengan full colour depan dan belakang supaya menarik perhatian/ dilihat.

Tabel 3.2 Data Hasil Penilaian Oleh Ahli Materi

\begin{tabular}{|c|c|c|c|c|c|}
\hline \multirow{2}{*}{ No } & \multirow{2}{*}{ Kriteria } & \multicolumn{3}{|c|}{ Skor } & \multirow{2}{*}{ Keterangan } \\
\hline & & $\mathbf{X}$ & $\mathbf{X i}$ & $\%$ & \\
\hline 1. & $\begin{array}{l}\text { Materi sesuai dengan KI/KD } 3.2 \\
\text { Menganalisis sistem perkembangan pada } \\
\text { tumbuhan dan hewan serta penerapan } \\
\text { teknologi pada sistem reproduksi tumbuhan } \\
\text { dan hewan./Kurikulum } 2013\end{array}$ & 5 & 5 & 100 & Sangat Layak \\
\hline 2. & $\begin{array}{l}\text { Materi yang disajikan sesuai dengan tujuan } \\
\text { pembelajaran }\end{array}$ & 4 & 5 & 80 & Layak \\
\hline 3. & Adanya kejelasan materi yang disajikan & 4 & 5 & 80 & Layak \\
\hline 4. & Penyampaian materi baik & 4 & 5 & 80 & Layak \\
\hline 5. & Gambar dan konsep sesuai dengan KD & 5 & 5 & 100 & Sangat Layak \\
\hline
\end{tabular}

ISSN Print $\quad: 1979-7141$

ISSN Online : 2541-1942 


\begin{tabular}{llcccl}
\hline \multirow{2}{*}{ No } & \multirow{2}{*}{ Kriteria } & \multicolumn{3}{c}{ Skor } & \multirow{2}{*}{ Keterangan } \\
\cline { 3 - 5 } & & $\mathbf{X}$ & $\mathbf{X i}$ & $\mathbf{\%}$ & \\
\hline 6. & Proses metamorfosis lebah lengkap & 5 & 5 & 100 & Sangat Layak \\
\hline 7. & Proses metamorfosis lebah runtut & 5 & 5 & 100 & Sangat Layak \\
\hline 8. & Bahasa sesuai dengan EYD & 4 & 5 & 80 & Layak \\
\hline 9. & Bahasa mudah dipahami & 4 & 5 & 80 & Layak \\
\hline 10. & Dapat memotivasi siswa & 4 & 5 & 80 & Layak \\
\hline & & $\mathbf{4 4}$ & $\mathbf{5 0}$ & $\mathbf{8 8}$ & Sangat Layak \\
\hline
\end{tabular}

Keterangan:

$\mathrm{X}=$ Skor dari Ahli Materi

$\mathrm{Xi}=$ Skor Maksimal

Total jawaban yang diperoleh dari ahli media adalah 44 dan skor maksimal dari jawaban secara keseluruhan adalah 50 maka dari perolehan skor keseluruhan dari ahli media diatas diperoleh nilai rata-rata $88 \%$ dengan kriteria sangat layak. Aspek materi yang disajikan sesuai dengan tujuan pembelajaran, aspek adanya kejelasan materi yang disajikan, aspek penyampaian materi baik, aspek bahasa sesuai dengan EYD, aspek bahasa mudah dipahami, dan aspek dapat memotivasi siswa mendapatkan nilai rata-rata $80 \%$ dengan kriteria 'layak'. Dari penilaian tersebut dapat disimpulkan bahwa perlu adanya perbaikan lebih lanjut dari segi materi guna lebih layak diterapkan dalam proses pembelajaran. Kritik dan saran dari ahli materi yaitu untuk lebih berkomunikasi dengan peserta didik.

4. Implementation (implementasi)

Pada tahap ini diimplementasikan rancangan dan metode yang telah dikembangkan pada situasi yang nyata yaitu di kelas. Selama implementasi, rancangan media Augmented Reality (AR) diterapkan pada kondisi yang sebenarnya. Materi disampaikan sesuai dengan media Augmented Reality (AR). Setelah penerapan media Augmented Reality (AR) kemudian dilakukan evaluasi awal untuk memberi umpan balik pada penerapan media Augmented Reality (AR) melalui angket.

Media Augmented Reality metamorfosis lebah diujicobakan pada 5 siswa MTs Al-Ihsan Kalijaring Jombang. Hasil tanggapan dari siswa dapat dilihat pada tabel 3.3.

Tabel 3.3 Data Hasil Uji Coba Pengguna

\begin{tabular}{|c|c|c|c|c|c|c|}
\hline \multirow{2}{*}{ No } & \multirow{2}{*}{ Aspek } & \multirow{2}{*}{ Kriteria } & \multicolumn{3}{|c|}{ Skor } & \multirow{2}{*}{ Keterangan } \\
\hline & & & $\sum \mathbf{X}$ & $\sum \mathbf{X i}$ & $\%$ & \\
\hline \multirow[t]{4}{*}{1} & Materi & $\begin{array}{l}\text { Saya mudah memahami materi dalam } \\
\text { Augmented reality }(A R)\end{array}$ & 4,20 & 5,00 & 84,00 & Sangat Setuju \\
\hline & & $\begin{array}{l}\text { Materi pada Augmented Reality }(A R) \\
\text { jelas }\end{array}$ & 4,00 & 5,00 & 80,00 & Setuju \\
\hline & & $\begin{array}{l}\text { Metemorfosis lebah pada Augmented } \\
\text { Reality }(A R) \text { lebih menarik }\end{array}$ & 5,00 & 5,00 & 100,00 & Sangat Setuju \\
\hline & & Rata-rata & 4,40 & 5,00 & $\mathbf{8 8 , 0 0}$ & Sangat Setuju \\
\hline 2. & Tampilan & $\begin{array}{l}\text { Tampilan dan komposisi warna media } \\
\text { Augmented Reality }(A R) \text { menarik }\end{array}$ & 4,20 & 5,00 & 84.00 & Sangat Setuju \\
\hline
\end{tabular}




\begin{tabular}{|c|c|c|c|c|c|c|}
\hline \multirow{6}{*}{ No } & \multirow{6}{*}{ Aspek } & \multirow{2}{*}{ Kriteria } & \multicolumn{3}{|c|}{ Skor } & \multirow{2}{*}{ Keterangan } \\
\hline & & & $\sum \mathbf{X}$ & $\overline{\sum \mathbf{X i}}$ & $\%$ & \\
\hline & & $\begin{array}{l}\text { Tampilan gambar dan video media } \\
\text { Augmented Reality }(A R) \text { jelas }\end{array}$ & 4,20 & 5,00 & 84,00 & Sangat Setuju \\
\hline & & $\begin{array}{l}\text { Tampilan animasi dalam media } \\
\text { Augmented Reality }(A R) \text { menarik }\end{array}$ & 4,40 & 5,00 & 88,00 & Sangat Setuju \\
\hline & & $\begin{array}{l}\text { Tampilan dan teks dalam media } \\
\text { Augmented Reality }(A R) \text { jelas dan mudah } \\
\text { dibaca }\end{array}$ & 4,20 & 5,00 & 84,00 & Sangat Setuju \\
\hline & & Rata-rata & 4,25 & 5,00 & 85,00 & Sangat Setuju \\
\hline \multirow[t]{3}{*}{3.} & Bahasa & $\begin{array}{l}\text { Media Augmented Reality }(A R) \\
\text { menggunakan kaidah bahasa indonesia } \\
\text { yang baik dan benar }\end{array}$ & 4,40 & 5,00 & 88,00 & Sangat Setuju \\
\hline & & $\begin{array}{l}\text { Bahasa yang digunakan Media } \\
\text { Augmented Reality }(A R) \text { sederhana dan } \\
\text { mudah di pahami }\end{array}$ & 5,00 & 5,00 & 100,00 & Sangat Setuju \\
\hline & & Rata-rata & 4,70 & 5,00 & 94,00 & Sangat Setuju \\
\hline \multirow[t]{3}{*}{4.} & Penyajian & $\begin{array}{l}\text { Media Augmented Reality }(A R) \text { mudah } \\
\text { dioperasikan }\end{array}$ & 4,20 & 5,00 & 84,00 & Sangat Setuju \\
\hline & & Media Augmented Reality (AR) menarik & 4,60 & 5,00 & 92,00 & Sangat Setuju \\
\hline & & Rata-rata & 4,40 & 5,00 & 88,00 & Sangat Setuju \\
\hline \multicolumn{3}{|c|}{ Total Rata-rata } & 4,44 & 5,00 & 88,75 & Sangat Setuju \\
\hline
\end{tabular}

Keterangan:

$\sum \mathrm{X}=$ Total Skor Rata-rata dari Seluruh Responden

$\sum \mathrm{Xi}=$ Total Skor Rata-rata Maksimal dari Seluruh Responden

Tabel 3.3 menunjukkan hasil dari angket respon siswa dan diperoleh nilai rata-rata presentase 88, $75 \%$ dengan kriteria 'sangat setuju'. Aspek materi kriteria materi Augmented Reality (AR) jelas mendapatkan nilai rata-rata $80 \%$ dengan kriteria 'setuju'. Pada data diatas diperoleh hasil nilai rata-rata tertinggi terdapat pada aspek bahasa dengan nilai rata-rata $94 \%$ dengan kriteria 'sangat setuju' dan nilai rata-rata terendah terdapat pada aspek tampilan yaitu dengan nilai rata-rata $85 \%$ dengan kriteria 'sangat setuju'. Melihat pada aspek tampilan yang mendapatkan nilai rata-rata terendah maka perlu adanya perbaikan yaitu mengenai tampilan dan pada media Augmented Reality (AR) agar dibuat lebih menarik lagi.

5. Evaluasi

Evaluasi bertujuan untuk menilai sebuah objek melalui penggunaan data dan informasi yang relevan. Evaluasi juga dapat diartikan sebagai sebuah proses sistematik yang dilakukan dalam merancang, mengumpulkan, melaporkan, dan menerapkan informasi untuk memutuskan nilai dan kegunaan dari sebuah objek (Pribadi, 2016). Evaluasi dilakukan untuk menghasilkan produk yang relevan dan layak digunakan sebagai media pembelajaran.

Berdasarkan saran dari ahli media perlu dilakukan beberapa evaluasi yang dapat dilihat pada tabel 3.4.

ISSN Print $\quad: 1979-7141$

ISSN Online : 2541-1942 
Tabel 4.5 Revisi Berdasarkan Saran dari Ahli

\begin{tabular}{lll}
\hline No & Point yang Direvisi & \multicolumn{1}{c}{ Visualisasi } \\
\hline 1. & Kartu AR & - Kartu AR menggunakan kertas yang lebih tebal \\
& & - Tampilan depan belakang dibuat full colour \\
& & - Pinggiran kartu dibuat melengkung (tidak lancip) \\
& & \\
\hline
\end{tabular}

Tampilan depan sebelum revisi

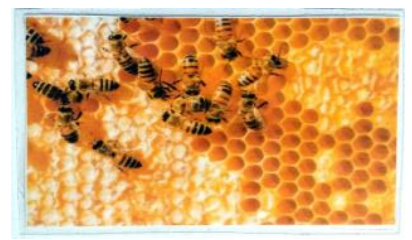

Tampilan depan sesudah revisi

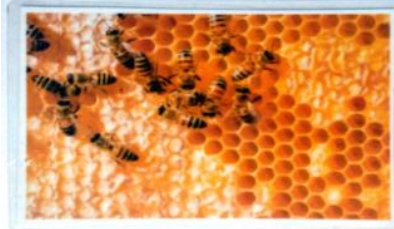

Tampilan belakang sebelum revisi

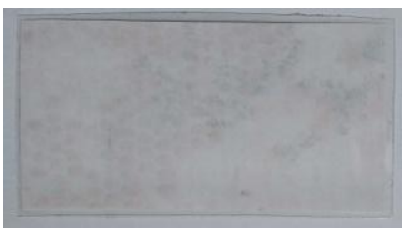

Tampilan belakang sesudah revisi

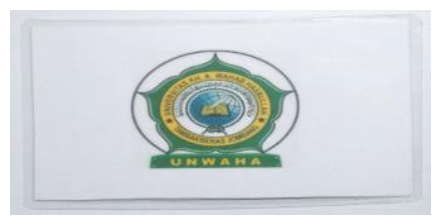




\section{KESIMPULAN}

Pengembangan media Augmented Reality (AR) pada metamorfosis lebah dinyatakan layak digunakan. Hal ini berdasarkan penilaian dari validator ahli media, validator ahli materi, dan beberapa responden dari siswa yang berjumlah 5 . Hasil validasi dari ahli media mendapatkan presentase $80 \%$ dengan kriteria layak, sedangkan hasil validasi dari ahli materi mendapatkan presentase $88 \%$ dengan kriteria sangat layak. Hasil uji coba pengguna (siswa) mendapatkan presentase $88,75 \%$ dengan kriteria sangat layak. Berdasarkan validasi dari ahli media, ahli materi dan uji coba pengguna (siswa) media Augmented Reality (AR) pada metamorfosis lebah dinyatakan layak digunakan sebagai bahan ajar. Berikut saran yang dapat diberikan :

1. Media Augmented Reality (AR) lebih dikembangkan lagi untuk bisa mencakup beberapa materi metamorfosis, bukan hanya pada lebah saja.

2. Tampilan pada media Augmented Reality (AR) dibuat lebih menarik lagi agar siswa tidak bosan.

3. Ukuran video/gambar dalam Augmented Reality (AR) dibuat sesuai dengan layar Handphone, agar ketika Handphone dijauhkan atau didekatkan tidak berpengaruh.

4. Diharapkan media Augmented Reality (AR) bisa disebarkan melalui Android, dikarenakan gambar menggunakan foto asli, maka media Augmented Reality pada metamorfosis lebah ini bisa digunakan untuk berbagai tingkatan sekolah, mulai dari tingkat Sekolah Dasar hingga Perguruan Tinggi bahkan untuk masyarakat umum. Untuk selanjutnya penulis akan mengusahakan agar bisa disebarkan ke Google Play agar para siswa juga bisa menggunakannya sendiri.

\section{DAFTAR PUSTAKA}

Mustika, D. 2015. Implementasi Augmented RealitySebagai Media Pembelajaran Interaktif. Citec Journal, 2(4): 277-290.

Mustaqim, I. 2016. Pemanfaatan Augmented Reality Sebagai Media Pembelajaran. Jurnal Pendidikan Teknologi dan Kejuruan, (Online), Vol 13, No. 2, (https://ejournal.undiksha.ac.id/index.php/JPTK/aticle/view/8525, diakses 11 Mei 2019).

Meishanti, OPY. 2020. Analisis Keterlaksanaan Praktikum Biologi Terhadap Hasil Belajar

Psikomotor Peserta Didik Kelas XI IPA di MA Al Ihsan Tembelang Jombang. Jurnal Eduscope (online). VOL. 6, No. 1,

http://ejournal.unwaha.ac.id/index.php/eduscope/article/view/874/433 diakses 31 Oktober 2020

Meishanti, OPY. 2018. Pelibatan Aktor Pendidikan Dalam System Three Way Traffic

Communication Untuk Meningkatkan Mutu Peserta Didik Sekolah Dasar Di Jombang. Jurnal Akrab Juara (online), Vol. 3, No. 1,

http://akrabjuara.com/index.php/akrabjuara/article/view/140 diakses 31 Oktober 2020

Meishanti, OPY. 2019. Pengaruh Pemberian Kuis Terhadap Hasil Belajar Siswa Kelas VII Di SMPN Bandarkedungmulyo Jombang. Jurnal Eduscope (Online), Vol. 4, No. 01, http://ejournal.unwaha.ac.id/index.php/eduscope/article/view/380/300 diakses 31 Oktober 2020

Pribadi, Dr, Benny A. 2016. Desain dan Pengembangan Program Pelatihan Berbasis Kompetensi: Implementasi Model ADDIE. Jakarta: Prenada Media Group.

Tim Dosen Jurusan Administrasi Pendidikan. 2008. Manajemen Pendidikan. Bandung: Alfabeta.

Young, J. C. 2015. Marketing Communication Menggunakan Augmented Reality. ULTIMATICS, 7(1): $14-1$

ISSN Print $\quad: 1979-7141$

ISSN Online : 2541-1942 